Pre-print Manuscript:

Bridgelall, R., and Tolliver, D. (2020). Closed Form Models to Assess Railroad Technology Investments.

Transportation Planning and Technology, Vol. 43, No. 7. DOI: 10.1080/03081060.2020.1805541.

\title{
Closed Form Models to Assess Railroad Technology Investments
}

Raj Bridgelall, Ph.D., Corresponding Author

Assistant Professor, Department of Transportation, Logistics \& Finance

College of Business, North Dakota State University

Fargo, ND 58108; Email: raj@bridgelall.com, ORCID: 0000-0003-3743-6652

\section{Denver D. Tolliver, Ph.D.}

Director, Upper Great Plains Transportation Institute, North Dakota State University

Fargo, ND 58108; Email: denver.tolliver@ndsu.edu, ORCID: 0000-0002-8522-9394

\section{Declarations of Interest: None.}

\begin{abstract}
Class I railroads in North America collectively invested $\$ 11.2$ billion to comply with a federal mandate to deploy positive train control. This amount dwarfs the potential savings from accidents the technology could prevent. Therefore, railroads must seek additional benefits. This research contributes simple closed-form models to inform strategies that can leverage the technology deployment by estimating the annual additional net benefits, internal rate of return, and benefit-cost ratio needed for a desired payback period.
\end{abstract}

Keywords: Benefit-cost analysis; internal rate of return; non-destructive evaluation; payback period; positive train control; railroad safety. 
24 The United States Congress established the Rail Safety Improvement Act of 2008 (RSIA08) in response to fatal train accidents caused by human error. As a countermeasure, the law mandated installation of a positive train control (PTC) system on:

1. Class I lines, which are those that carry more than five million gross tons annually, and over which trains transport any poisonous- or toxic-by-inhalation $(\mathrm{PIH} / \mathrm{TIH})$ hazardous materials.

2. Any railroad's main lines that operate regularly scheduled passenger intercity or commuter rail.

PTC is a communications-based train control technology that can stop a train automatically before accidents due to human error can occur (GAO, 2010). PTC uses signals and sensors along the track to communicate train location, speed restrictions, and moving authority. Manufacturers designed PTC to prevent train-to-train collisions, derailments due to excessive speed, unauthorized entry into established work zone limits, and the movement of a train through an improperly lined switch (Badugu \& Movva, 2013). Hence, the system must be able to precisely determine train speed and location, warn operators about potential issues, and control the train within a few seconds if the operator fails to respond to warnings (FRA, 2018). A typical PTC system contains more than 20 major components. Figure 1 shows the typical architecture of a PTC system. [Figure 1 near here]. Most of those components were not available prior to the introduction of PTC, and designs are still evolving to assure interoperability. The installation of a PTC system involves the following three segments (AAR, 2018):

1. Locomotive: contains on-board computers, a location tracking system, and a digital data link to manage train speed. 
2. Wayside: contains devices that monitor signals, track switches, track circuits, and lamps, among other things. These devices communicate with the train via radio towers to authorize movement; the devices also communicate with the central office systems over $220 \mathrm{MHz}$ (PTC 220) radios, Wi-Fi, cellular, or Ethernet to provide system status.

3. Central Office: contains dispatcher interfaces and computers that store and act on information from train systems, wayside systems, and maintenance personnel. These systems exchange messages over both wired and wireless connections.

The federal mandate resulted in an installation scope of more than 40 railroads that includes all seven Class I freight railroads, many passenger railroads, and a few short-line railroads (FRA, 2018). The Federal Railroad Administration (FRA) estimated that PTC implementation would cover approximately 60,000 route miles of the 140,000-mile railroad network that carries more than 20,000 locomotives. The RSIA08 required that railroads complete PTC implementations by the end of 2015. However, in October 2015, Congress extended that deadline to the end of 2018, with further extensions allowed through 2020 to test newly installed systems (AAR, 2018).

A Government Accountability Office (GAO) analysis of FRA accident data from 2000 to 2009 found that $35 \%$ of the accidents were due to human factors (GAO, 2010). According to the Association of American Railroads (AAR), human error was the leading factor in $25 \%$ of mainline train accidents from 2013 to 2017 (AAR, 2018). One major limitation of PTC systems is that they cannot prevent accidents at rail-grade crossings, incidents involving people trespassing on tracks (Lobb, 2006), or occasions when track segments or equipment malfunctions. A Congressional Research Service (CRS) report, updated in 2018, stated that PTC would not prevent the majority of rail-related fatalities from pedestrians trespassing on railroad tracks or motor vehicle crashes at rail-grade crossings (Peters \& Frittelli, 2018). The report noted 
that train derailments or collisions, which PTC could prevent, caused relatively few fatalities. Concerning the perceived negligible benefits of PTC relative to its deployment cost, the National Transportation Safety Board (NTSB) testified to Congress that since 1969, PTC could have prevented the loss of 300 lives (Sumwalt (III), 2018).

U.S. Class I railroads own and maintain the majority of U.S. freight track miles (AAR, 2018). Hence, compliance with safety and other regulations presents significant economic challenges. Nevertheless, this problem is not unique, as railroads around the world face similar challenges (Friebel, McCullough, \& Angulo, 2014). There is a scarcity of data about the actual costs and benefits of PTC deployments because of the proprietary nature of U.S. railroad implementations, and the rush to comply with the 2018 mandate. Furthermore, the lack of standards and the variety of technologies available to achieve the implementation goals resulted in widely varying deployments. PTC implementation also presents new challenges, such as cybersecurity, big data mining, system failures, and interoperability (Zhang, Liu, \& Holt, 2018). During the first half of the implementation deadline year, the FRA had approved and certified 10 different types of PTC systems (FRA, 2018). After the first quarter of that year, only one of the seven major Class I railroads achieved interoperability with some of their tenant railroad's PTC system (FRA, 2018). Even so, only $29 \%$ of their tenant railroads achieved interoperability by the end of the third quarter of the compliance year.

Previous analyses about PTC deployment costs are dated. A study commissioned by the FRA in 2009 determined that the total cost for PTC implementation over 20 years could range from $\$ 10$ billion to $\$ 13.8$ billion (Roskind, 2009). Peabody \& Associates, Inc. revised the analysis in 2010 to include other direct, indirect, and societal costs that increased the total estimate to $\$ 15.2$ billion (L. E. Peabody \& Associates, Inc., 2010). A Canadian working group 
on rail safety estimated that the average Class I railroad PTC implementation cost was $\$ 192,000$ per route mile (Advisory Council on Railway Safety (ACRS), 2016), which equates to \$11.5 billion for the U.S. network. In 2018, the USDOT estimated that, not including Class I railroads, the 37 railroads that collectively received $\$ 2.9$ billion in grants would spend $\$ 4.2$ billion to implement PTC (DeWeese, 2018). Hence, the total estimate for all railroads was $\$ 15.7$ billion $(11.5+4.2)$, which is consistent with the Peabody \& Associates estimate. Beyond the initial deployment cost, railroads will need to maintain the PTC system. The 2009 FRA-commissioned study estimated that the annual maintenance cost for PTC deployments would be approximately $15 \%$ of the accumulated deployment investment (Roskind, 2009). In 2016, the American Public Transportation Association (APTA) estimated that commuter railroads would spend $\$ 100$ million each year to operate and maintain PTC installations (DeWeese, 2018).

The most recent analysis of potential PTC benefits was eight years prior to the mandated deadline year of 2018. The 2009 FRA-commissioned study found that railroads would realize $\$ 90$ million in annual safety benefits after full implementation of PTC (Roskind, 2009). It is clear that the potential savings from accident risk reduction dwarfs the estimated PTC deployment costs. Hence, railroads must seek additional net benefits from PTC deployments to recover their investments. In particular, the installed infrastructure of sensor interfaces and wireless networks provides opportunities to realize additional benefits from incremental investments in interface systems. For example, overlay sensors could monitor rail-grade crossings and provide real-time diagnostics. Non-human factors such as track irregularities are a common cause of accidents (Liu, Saat, \& Barkan, 2017). Therefore, on-board sensors could use the PTC network to communicate data relating to track irregularities (Chia, Bhardwaj, Lu, \& 
114 Bridgelall, 2018). Other potential benefits could include business enhancements, such as

115 improved line capacity, service reliability, equipment utilization, and fuel savings.

116 A closed-form model to predict net additional benefits needed, the internal-rate-of-return

117 (IRR), and the benefit-cost-ratio (BCR) within a fixed period is generally not directly realizable.

118 Hence, the main contribution of this paper are simple closed-form models to inform planning

119 strategies by estimating the additional net benefits needed as a function of the payback period, 120 given the initial investment to deploy PTC systems. Subsequently, the goals of this research are 121 to:

122

123

124

125

126

127

128

129

130

131

132

133

134

135

136

1. Estimate the cost of PTC deployments based on data gathered from various railroad company reports.

2. Estimate the financial loss from railroad accidents that PTC implementations may have prevented.

3. Develop a simple model to the estimate the net additional benefits needed to achieve a desired payback period by conducting a benefit-cost analysis (BCA) with FRA recommended discount rates.

4. Develop simple models to estimate the IRR and the BCR, given a series of net additional benefits needed to achieve a desired payback period.

The organization of the remainder of this paper is as follows: Section 2 describes the BCA method and optimization procedure used to determine the net additional benefits needed as a function of the payback period, the corresponding IRR, and the 10-year BCR. Section 3 summarizes the stated 2018 costs of PTC deployments and identifies the data sources. Section 4 summarizes the Class I railroad reported financial losses from all accidents during the five years prior to the mandate year. The analysis also computes the proportion of financial loss that PTC 
137 deployments could have prevented. Section 4 uses the financial loss data to compute the net

138 additional benefits needed as a function of payback period. The section also estimates a simple

139 model that best fits the computed data points. Section 5 discusses the potential for realizing

140 additional net benefits from PTC deployments. Section 6 offers concluding remarks about the

141 possible generalization and utility of the research contribution.

142

143

144

145

146

147

148

149

150

151

152

\section{Methods}

More than 600 railroads in the U.S. freight rail industry utilize the 140,000 miles of rail network (AAR, 2018). Approximately 97\% of the network carries freight, and Class I railroads dominate those movements. Hence, this analysis focuses on data from Class I railroads. The cost estimates are the publicly disclosed expenditures accumulated for full PTC implementations. Some of these cost data are scattered among press releases, financial statements, and government reports.

Mining data from the FRA accident database for the five years preceding the 2018 mandate provided an estimate of the potential savings from accidents that PTC could have prevented. The premise was that a fully implemented and reliable PTC system could have prevented all accidents due to human factors or failures in the existing signalling and communication systems. This analysis used the railroad reported financial losses as the potential savings from accident avoidance.

The cumulative discounted net benefit, which is a return on the investment $(R)$, is

$$
R=\sum_{i=1}^{n} \frac{B_{i}-C_{i}}{(1+r)^{i}}
$$

The variable $r$ is the discount rate, $i$ is the future year, and $n$ is the total number of years for payback. Per the FRA guidelines for BCA, the model uses discount rates of $7 \%$ and $3 \%$ for payback period calculation and sensitivity assessments, respectively (FRA, 2016). Based on the 
2009 FRA-commissioned study (Roskind, 2009), the model used 15\% of the initial deployment investment as the average annual cost $C_{i}$ for operating and maintaining the PTC system. Subsequently, the optimization problem was to determine the annual average net benefits $B_{i}$ needed to achieve a payback period of $n$ years. The annual average net benefits are the actual benefits minus the costs needed to achieve them. The objective function was $R-I=0$ where $I$ was the initial investment for PTC deployment. The constraint was that the annual average net benefits $B_{i}$ as a proportion of the initial investment $I$ must be positive.

Given the solution for $B_{i}$ as a function of payback period years, the internal rate of return (IRR) is the value of $r$ that satisfies the following equation:

$$
\sum_{i=1}^{n} \frac{B_{i}-C_{i}-I_{i}}{(1+r)^{i}}=0
$$

where $I_{0}=I$ is the initial investment, and future year investments are zero. Subsequently, the BCR is based on a customary 10-year period (FRA, 2016), and is given as

$$
B C R=\sum_{i=1}^{10} \frac{B_{i}}{(1+r)^{i}} / I
$$

Iteratively solving the equations as a function of the desired payback years produced a set of data points. Subsequently, estimating the closed form predictive function used a standard method, such as the minimization of a means-squared-error.

\section{Data}

\subsection{Deployment Costs}

Class I railroads collectively reported a total cost of $\$ 11.2$ billion for PTC deployments. Table 1 summarizes the Class I railroad stated 2018 costs, and the source of those data. The railroad PTC implementation progress reports are located at the website: https://www.fra.dot.gov/Page/P0628 [Table 1 near here] 


\subsection{Accident Prevention}

The industry's expectation is that a fully functioning, reliable, and back-office monitored PTC system should be capable of circumventing nearly all failures due to human factors and failures in the signalling and communications systems. Together, this study considers those factors as PTC-addressable (PTC-A). The FRA database (FRA, 2018) classifies the causes of accidents into one of the following categories:

1. Mechanical and electrical failures (for example, axles, bearings, locomotive/truck components, wheels, brakes)

2. Rack, roadbed and structures (for example, track geometry, broken rail, defective switches/frogs, settled roadbed)

3. Train operation - human factors (for example, poor throttling/braking, ignore signals/rules/orders, drowsy, ill)

4. Signal \& communications failure (for example, automatic stop device, power switch, radio, computer, remote control)

5. Miscellaneous (for example, environmental conditions, loading procedures, vandalism)

One limitation of this dataset is that it contains information about accidents reported by the railroads involved, and that those reports are required only for accidents that resulted in damages in excess of an annually adjusted threshold of $\$ 10,500$. According to the FRA website, the reported financial loss from accident damages include the loss and/or repair of cars and locomotives, the repair of signal systems and other structures, and the repair of roadbed and track. Not included are financial losses associated with clean up, lost freight, societal damages, fatalities, injuries, and line closures. 
202 This section summarizes results from the analysis of financial loss from accidents, the benefit203 cost assessment, and estimation of the benefit prediction model.

204

205

206

207

\subsection{Financial Loss}

Table 2 summarizes the five years of FRA accident data before the mandate year of 2018 . The average number of annual Class I railroad accidents were 1,774 (row labelled AVG). [Table 2 near here]. The standard deviation (STD) was 102.4, thus the coefficient of variation (CV) was $5.8 \%$. This indicates a relatively high consistency in annual accident occurrence. Therefore, using the average of those historical values is justifiable for quantifying the potential financial benefits from avoiding those types of accidents. For that period, accidents due to human factors or failures in signaling and communication systems (PTC-A) accounted for $44.6 \%$ of the average annual accidents. This is comparable to the GAO 2010 estimate of $49 \%$ for the 2000 to 2009 years. The PTC avoidable accidents amounted to $31.6 \%$ of the average annual financial loss (TFL). Hence, had there been a PTC system that worked flawlessly, Class I railroads collectively would have avoided nearly $45 \%$ of those accidents, which amounted to nearly $\$ 92$ million in average annual financial losses (PTC-A FL).

\subsection{Benefit Cost Assessment}

Table 3 lists the net additional annual benefits, beyond accident avoidance, that the Class I railroads need collectively to achieve the payback period listed. [Table 3 near here]. The table lists the additional net annual benefits as a proportion of the total Class I railroad initial investment to achieve the mandated deployment. The table also lists the IRR and the 10-year BCR for the $3 \%$ and $7 \%$ discount rates. One data point is that at a $3 \%$ discount rate, Class I railroads must realize an additional net annual benefit of nearly $26 \%$ of the initial PTC 
224 investment to achieve a payback within 10 years. The additional net annual benefits increase to

$22528.4 \%$ with a discount rate of $7 \%$. The IRR for 10 years of those additional net benefits amounts

226 to $10 \%$ and $13 \%$ for discount rates of $3 \%$ and $7 \%$, respectively. Figure 2 and Figure 3 plots the

227 data in Table 1 for the $3 \%$ and $7 \%$ discount rates, respectively. It is evident that the data follows

228 a non-linear trend. [Figure 2 near here]. [Figure 3 near here].

229

230

231

232

\subsection{Model Estimation}

Figure 2 plots power model estimates of the data in Table 3. The model form for the three variables of benefit proportion, IRR and BCR, as a function of payback years is a power form such that:

$$
B=\alpha i^{-\beta}
$$

The estimated parameters are $\alpha$ and $\beta . B$ is one of the three predicted variables and $i$ is the payback year. Table 4 summarizes the model parameter estimates and the coefficient of determination $\mathrm{R}^{2}$ for the best fit to the data. [Table 4 near here]. The consistently high coefficient of determination indicates that the power model is a good estimator for the predicted variables as a function of the desired payback period.

\section{Discussion}

Railroads can leverage the installed PTC communications infrastructure to enhance safety further and to realize additional business benefits. However, the assessment of potential benefits has been controversial, largely because of the uncertainties involved. It is possible to use the PTC communications framework to add different types of sensors that could potentially prevent other types of accidents. In particular, the PTC framework has the potential to accommodate additional sensors at rail-grade crossings to detect oncoming trains if the crossing gate malfunctions, or to detect vehicles on the tracks. Recognizing this potential, Congress charged 
the FRA with studying the potential effectiveness of PTC technology in preventing gradecrossing incidents (Peters \& Frittelli, 2018).

According to the AAR, issues with track and equipment were responsible for $54 \%$ of mainline train accidents from 2013 to 2017 (AAR, 2018). Hence, the ability to monitor continuously the health of installed equipment and track conditions would contribute toward further overall accident reduction. For example, a fully deployed PTC infrastructure could support the incremental addition of train inspection devices, such as wayside defective bearing detectors (WDBD). Since defective bearings can lead to derailments, railroads can update their PTC software to stop a train for inspection if the WDBD units identify any defects. The PTC infrastructure could also accommodate train inspection devices that already exist by using interface translation devices. Interfaces to existing detectors could include wheel-impact load detector (WILD) that measure the condition of the wheel surface, and truck hunting detectors that monitor for excessive lateral oscillations. Other non-destructive evaluation (NDE) devices could include machine vision systems that use lasers to analyse wheel profiles while a train is in motion.

To realize additional savings, railroads can use the PTC network and back office computer upgrades to monitor and manage the health of installed equipment. The ability to monitor in realtime the operational status of installed technology can improve reliability, minimize down time, and optimize maintenance practices. According to the FRA, societal benefits from railroad projects could include enhancements in air quality, mobility, and transportation system connectivity (FRA, 2016). To enhance business efficiencies, railroads can use the PTC data links to exchange information about locomotive health, work orders, job status, and crew schedules in real time. If business efficiency gains lead to lower cost services that encourage a diversion of 
freight from trucks, then societal benefits could include reductions in overall fuel consumption and reduction of truck accidents. Future research will investigate other potential business benefits of PTC in detail because such an analysis is outside the scope of this article.

\section{Conclusions}

Railroad accidents of any type represent huge financial losses, regardless of the number of fatalities involved. Therefore, policies to prevent accidents will provide a financial benefit. To comply with the Rail Safety Improvement Act of 2008, Class I railroads and other railroads that meet certain conditions had to complete installation of positive train control (PTC) systems by the end of 2018. Railroads view PTC implementation as one of their most complex and expensive undertakings. Analysis of the Federal Railroad Administration (FRA) accident database found that PTC preventable accidents in the decade prior to the deployment mandate year of 2018 accounted for nearly $45 \%$ of Class I railroad accidents. Those accidents amounted to an equivalent of nearly $\$ 92$ million in annual financial losses. Class I railroads collectively reported their PTC deployment costs accumulated to more than $\$ 11$ billion by the end of the congressionally mandated deployment year of 2018. Hence, it is clear that PTC deployment costs greatly exceed the potential safety benefits from preventing financial losses due to accidents. Therefore, railroads must seek additional net benefits from PTC deployments to recover their investments.

A closed form model to predict net additional benefits needed, the IRR, and the BCR is generally not directly realizable for a spreadsheet model of BCA. This research developed a simple closed form model to predict the additional net benefits needed as a function of payback years. Using discount rates of 3\% and 7\%, one data point is that Class I railroads need to realize an additional net annual benefit of nearly $26 \%$ and $28 \%$ of the initial investment, respectively, to 
292 achieve a payback within 10 years. The corresponding IRR was $10 \%$ and $13 \%$, respectively.

293 Plotting the solutions for payback years from one to 20 revealed a simple closed form expression

294 as a power function with only two parameters. The parameter estimation for benefit proportion,

295 IRR, and 10-year BCR produced a high coefficient of determination with $\mathrm{R}^{2}$ values ranging from

$29695.7 \%$ to $99.9 \%$. For consistency with previous FRA-commissioned analysis, this assessment

297 used a proportional annual maintenance cost of 30\%. However, the methodology presented can

298 estimate a model based on any other level of initial investment and proportional annual

299 maintenance cost.

$300 \quad$ Railroads can use the simple closed-form model to inform planning strategies by providing

301 quick estimates of the net annual proportional benefits required to achieve a desired payback

302 period, given their initial investment and projected operating and maintenance costs. To achieve

303 net additional benefits, railroads must seek to leverage the installed infrastructure of sensor

304 interfaces and wireless networks to realize further enhancements in safety and business

305 efficiencies. Those benefits could include rail-grade safety sensors and potential business

306 enhancements, such as improved line capacity, service reliability, equipment utilization, real-

307 time diagnostics, fuel savings, and non-destructive evaluations. Future work will examine the

308 potential benefits and incremental costs of using the installed PTC infrastructure to achieve 309 autonomous operations.

\section{Acknowledgement}

311 This research did not receive any specific grant from funding agencies in the public, commercial, 312 or not-for-profit sectors. 
AAR. (2018, August 7). Freight Rail \& Positive Train Control: Technology Enhancing an Already Safe Network. (Association of American Railroads) Retrieved August 7, 2018, from https:/www.aar.org/article/freight-rail-positive-train-control/

AAR. (2018). Positive Train Control (PTC). Washington, D.C.: Association of American Railroads (AAR).

Advisory Council on Railway Safety (ACRS). (2016). Train Control Working Group Final Report. Ottawa, Ontario: Transport Canada. Retrieved from https://www.tc.gc.ca/media/documents/railsafety/train-control-working-group-finalreport.pdf

Badugu, S., \& Movva, A. (2013). Positive train control. International Journal of Emerging Technology and Advanced Engineering, 3(4), 304-307.

BNSF Railway. (2018, August 7). Leading the Way in PTC. (BNSF Railway) Retrieved August 7, 2018, from http://www.bnsf.com/in-the-community/safety-and-security/positive-traincontrol.html

Canadian National Railway. (2018, January 23). CN targeting record C\$3.2 billion capital program in 2018. (Canadian National Railway) Retrieved August 7, 2018, from https://www.cn.ca/en/news/2018/01/pressrelease_20180123040328_1353/

Chia, L., Bhardwaj, B., Lu, P., \& Bridgelall, R. (2018). Railroad Track Condition Monitoring Using Inertial Sensors and Digital Signal Processing: A Review. IEEE Sensors Journal, 19(1), 25033. doi:10.1109/JSEN.2018.2875600

DeWeese, B. J. (2018). Observations on Federal Funding Support for Positive Train Control Implementation. United States Department of Transportation (USDOT), Office of Inspector General. Washington, D.C.: USDOT.

FRA. (2016). Benefit-Cost Analysis Guidance for Rail Projects. Washington, D.C.: Federal Railroad Administration, U.S. Department of Transportation.

FRA. (2018, 11 27). Accident Data as reported by Railroads. (Federal Railroad Administration (FRA) Office of Safety Analysis) Retrieved 11 27, 2018, from https://safetydata.fra.dot.gov/officeofsafety/publicsite/on_the_fly_download.aspx

FRA. (2018). Federal Funding Support for Positive Train Control Implementation. United States Department of Transportation, Office of Inspector General. Washington, D.C.: Federal Railroad Administration.

FRA. (2018, August 7). PTC System Information. (Federal Railroad Administration (FRA)) Retrieved August 7, 2018, from https://www.fra.dot.gov/Page/P0358

Friebel, G., McCullough, G., \& Angulo, L. P. (2014). Patterns of Restructuring The US Class 1 Railroads from 1984 to 2004. Journal of Transport Economics and Policy, 48(1), 115135.

GAO. (2010). Rail Safety: Federal Railroad Administration Should Report on Risks to the Successful Implementation of Mandated Safety Technology. Washington, D.C.: Government Accountability Office. 
L. E. Peabody \& Associates, Inc. (2010). Positive Train Control Benefits Analysis: Updated Statement of Total Benefits and Restatement of FRA Cost-Benefit Analysis Based on FRA Costs and Updated Benefits. Alexandria, Virginia: The Chlorine Institute, Inc.

Liu, X., Saat, M. R., \& Barkan, C. P. (2017). Freight-train derailment rates for railroad safety and risk analysis. Accident Analysis \& Prevention, 98, 1-9. doi:10.1016/j.aap.2016.09.012

Lobb, B. (2006). Trespassing on the tracks: a review of railway pedestrian safety research. Journal of Safety Research, 37(4), 359-365. doi:10.1016/j.jsr.2006.04.005

Norfolk Southern Railway. (2017, March 30). A Trip to the Moon for Today's Generation of Railroaders. (Norfolk Southern Railway) Retrieved August 7, 2018, from http://www.nscorp.com/content/nscorp/en/bizns/a-trip-to-themoonfortodaysgenerationofrailroaders.html

Peters, J. C., \& Frittelli, J. (2018). Positive Train Control (PTC): Overview and Policy Issues. Washington, D.C.: Congressional Research Service (CRS). Retrieved from https://www.everycrsreport.com/reports/R42637.html

Roskind, F. D. (2009). Positive Train Control Systems Economic Analysis. United States Department of Transportation (USDOT), Federal Railroad Administration, Office of Safety Analysis. Washington, D.C.: USDOT.

Sumwalt (III), R. L. (2018). Testimony on Oversight of Positive Train Control Implementation in the United States. Washington, DC: National Transportation Safety Board (NTSB). Retrieved from https://www.ntsb.gov/news/speeches/RSumwalt/Documents/sumwalt20180215.pdf

Union Pacific Railroad. (2018, August 7). Positive Train Control. (Union Pacific Railroad) Retrieved August 7, 2018, from https://www.up.com/media/media_kit/ptc/about-ptc/

Zhang, Z., Liu, X., \& Holt, K. (2018). Positive Train Control (PTC) for railway safety in the United States: Policy developments and critical issues. Utilities Policy, 51(2018), 33-40. 


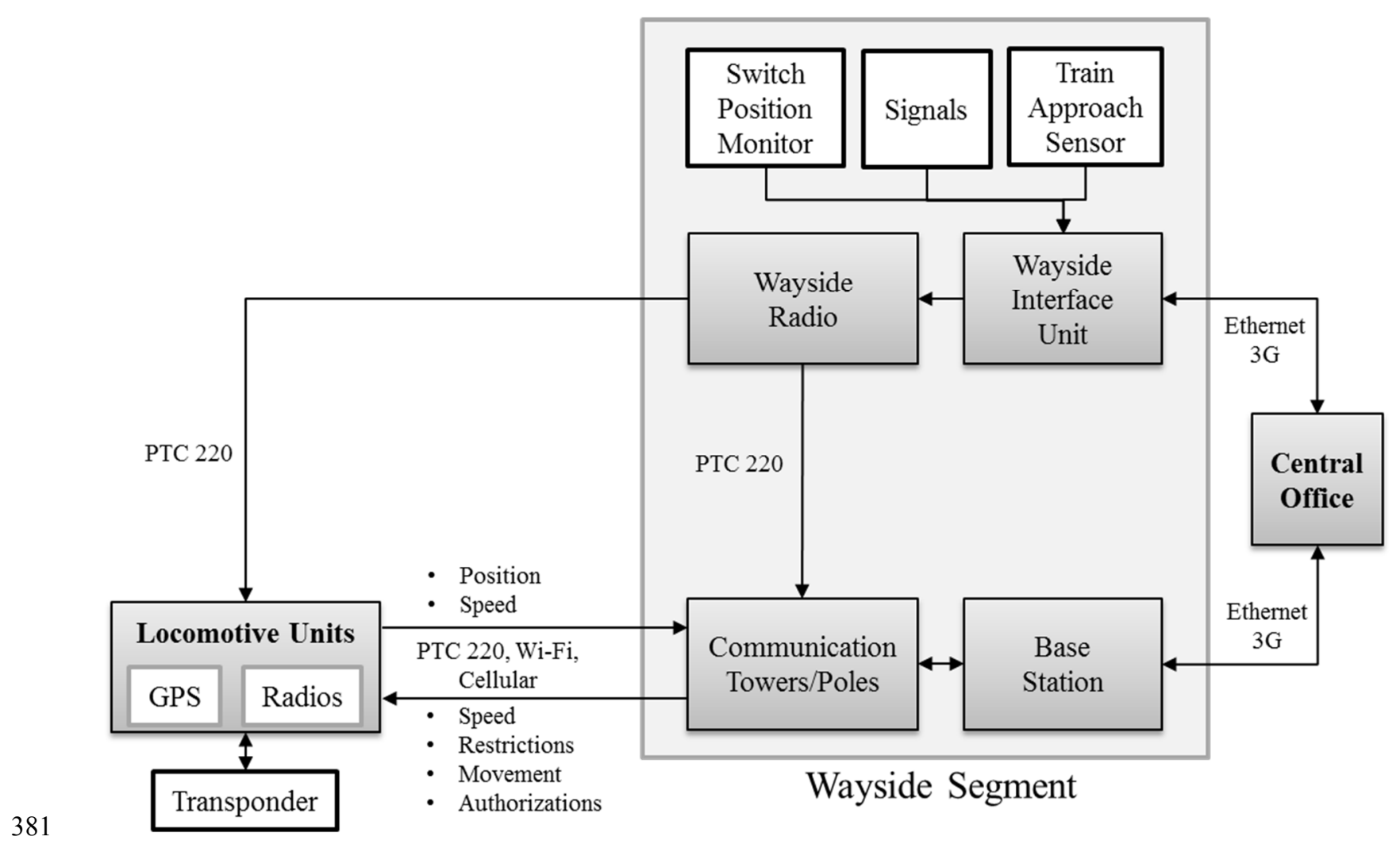

Fig 1. A typical architecture of PTC systems 


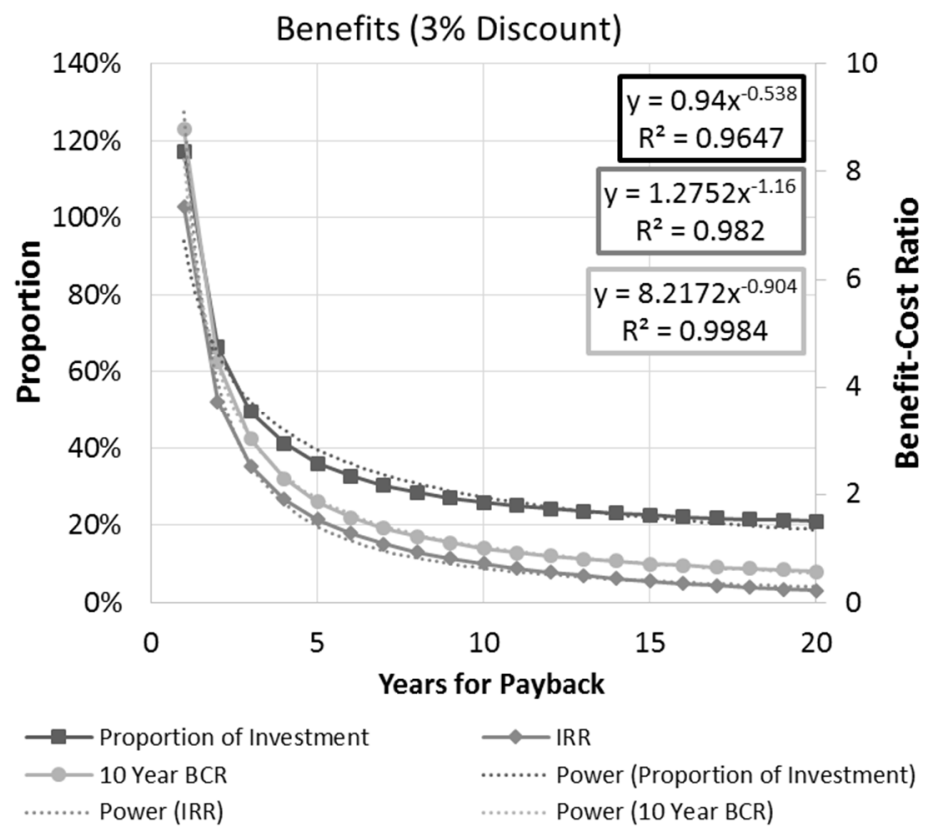

Fig 2. Benefits needed at 3\% discount rate as a function of payback period

386 


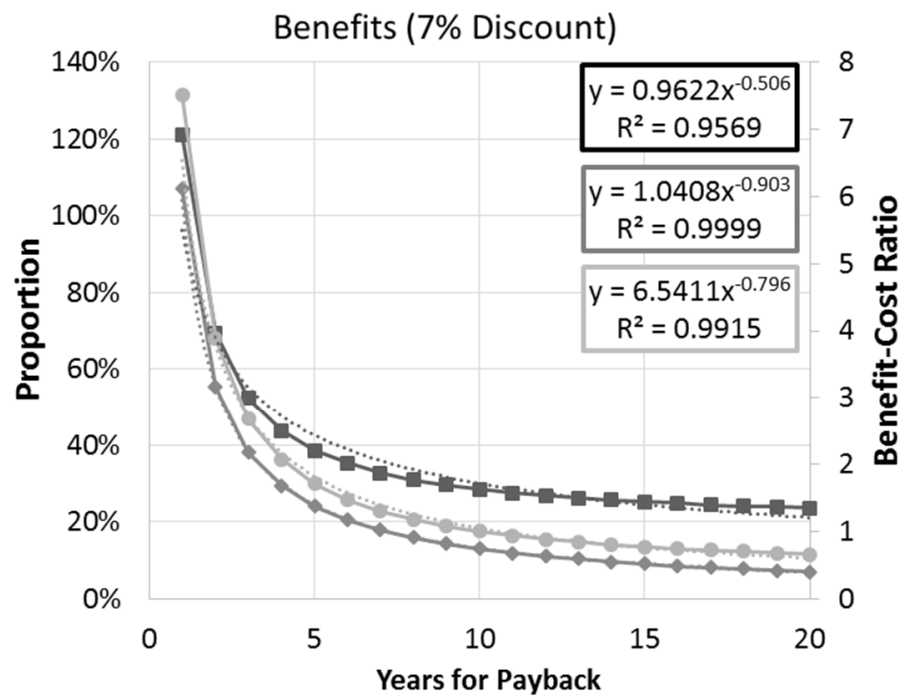

Fig 3. Benefits needed at $7 \%$ discount rate as a function of payback period 
390 Table 1. Sources for the Class I Railroad Stated Deployment Costs

\begin{tabular}{lrl}
\hline Railroad & Cost (\$B) & Source \\
\hline Union Pacific Railroad & 2.900 & $\begin{array}{l}\text { Company webpage on PTC } \\
\text { (Union Pacific Railroad, 2018) }\end{array}$ \\
BNSF Railway & 2.000 & $\begin{array}{l}\text { Company webpage on PTC } \\
\text { (BNSF Railway, 2018) }\end{array}$ \\
CSX Transportation & 2.400 & $\begin{array}{l}\text { CRS 2018 Report } \\
\text { (Peters \& Frittelli, 2018) } \\
\text { Company news webpage } \\
\text { Norfolk Southern Railway }\end{array}$ \\
1.800 & 1.400 & $\begin{array}{l}\text { Company press release } \\
\text { (Canadian National Railway, 2018) }\end{array}$ \\
Canadian National Railway & 0.300 & $\begin{array}{l}\text { USDOT Report on Grant Distribution } \\
\text { (DeWeese, 2018) }\end{array}$ \\
Kansas City Southern Railway & 0.375 & $\begin{array}{l}\text { Canadian Working Group Report } \\
\text { (Advisory Council on Railway Safety (ACRS), 2016). }\end{array}$ \\
Canadian Pacific Railway & & \\
\hline
\end{tabular}

391

392 
393 Table 2. Financial Losses from Human, Signalling, and Communication Errors

\begin{tabular}{rrrrrrr}
\hline Year & Accidents & PTC-A & PTC-A (\%) & TFL (\$) & PTC-A FL (\$) & PTC-A FL (\%) \\
\hline 2013 & 1806 & 771 & 42.7 & $361,341,622$ & $120,788,225$ & 33.4 \\
2014 & 1836 & 789 & 43.0 & $296,289,876$ & $86,366,068$ & 29.1 \\
2015 & 1892 & 993 & 52.5 & $311,490,762$ & $90,034,696$ & 28.9 \\
2016 & 1650 & 679 & 41.2 & $253,430,453$ & $96,279,982$ & 38.0 \\
2017 & 1686 & 724 & 42.9 & $226,583,986$ & $64,887,319$ & 28.6 \\
\hline AVG & 1774 & 791.2 & 44.6 & $289,827,340$ & $91,671,258$ & 31.6 \\
STD & 102.4 & 120.7 & & $52,320,684$ & $20,107,467$ & 4.1 \\
CV (\%) & 5.8 & 15.3 & & & & \\
\hline
\end{tabular}

394

395

396 
Table 3. Results of the Benefit Cost Analysis

\begin{tabular}{ccccccc}
\hline & 3\% Discount & & \multicolumn{3}{c}{$\mathbf{7 \%}$ Discount } \\
\hline $\begin{array}{c}\text { Payback } \\
\text { Years }\end{array}$ & $\begin{array}{c}\text { Additional Net } \\
\text { Benefits (\%) }\end{array}$ & IRR (\%) & $\begin{array}{c}\mathbf{1 0 Y r} \\
\text { BCR }\end{array}$ & $\begin{array}{c}\text { Additional Net } \\
\text { Benefits (\%) }\end{array}$ & IRR (\%) & $\begin{array}{c}\text { 10-Yr } \\
\text { BCR }\end{array}$ \\
\hline 1 & 117.2 & 103.0 & 8.79 & 121.2 & 107.0 & 7.52 \\
2 & 66.4 & 52.2 & 4.46 & 69.5 & 55.3 & 3.88 \\
3 & 49.5 & 35.3 & 3.02 & 52.3 & 38.0 & 2.68 \\
4 & 41.1 & 26.7 & 2.29 & 43.7 & 29.4 & 2.07 \\
5 & 36.0 & 21.4 & 1.86 & 38.6 & 24.1 & 1.71 \\
6 & 32.6 & 17.8 & 1.57 & 35.2 & 20.5 & 1.47 \\
7 & 30.2 & 15.1 & 1.37 & 32.7 & 17.9 & 1.30 \\
8 & 28.4 & 13.0 & 1.22 & 30.9 & 15.9 & 1.18 \\
9 & 27.0 & 11.3 & 1.10 & 29.5 & 14.3 & 1.08 \\
$\mathbf{1 0}$ & $\mathbf{2 5 . 9}$ & $\mathbf{1 0 . 0}$ & $\mathbf{1 . 0 0}$ & $\mathbf{2 8 . 4}$ & $\mathbf{1 3 . 0}$ & $\mathbf{1 . 0 0}$ \\
11 & 25.0 & 8.8 & 0.92 & 27.5 & 11.9 & 0.94 \\
12 & 24.2 & 7.8 & 0.86 & 26.8 & 11.0 & 0.88 \\
13 & 23.6 & 7.0 & 0.80 & 26.1 & 10.3 & 0.84 \\
14 & 23.0 & 6.2 & 0.76 & 25.6 & 9.6 & 0.80 \\
15 & 22.6 & 5.5 & 0.71 & 25.2 & 9.0 & 0.77 \\
16 & 22.1 & 4.9 & 0.68 & 24.8 & 8.5 & 0.74 \\
17 & 21.8 & 4.4 & 0.65 & 24.4 & 8.1 & 0.72 \\
18 & 21.5 & 3.9 & 0.62 & 24.1 & 7.7 & 0.70 \\
19 & 21.2 & 3.4 & 0.60 & 23.9 & 7.3 & 0.68 \\
20 & 20.9 & 3.0 & 0.57 & 23.6 & 7.0 & 0.66 \\
\hline
\end{tabular}

398

399

400 
Table 4. Model Parameter Estimates

\begin{tabular}{r|ccr|ccc|crr}
\cline { 2 - 10 } & \multicolumn{3}{|c|}{ Benefit Proportion } & \multicolumn{4}{c|}{ IRR } & \multicolumn{3}{c}{ BCR (10-Yr) } \\
\hline Discount Rate & $\alpha$ & $\beta$ & $\mathrm{R}^{2}(\%)$ & $\alpha$ & $\beta$ & $\mathrm{R}^{2}(\%)$ & $\alpha$ & $\beta$ & $\mathrm{R}^{2}(\%)$ \\
\hline $3 \%$ & 0.94 & 0.54 & 96.5 & 1.28 & 1.16 & 98.2 & 8.22 & 0.90 & 99.8 \\
\hline $7 \%$ & 0.96 & 0.51 & 95.7 & 1.04 & 0.90 & 99.9 & 6.54 & 0.80 & 99.2 \\
\hline
\end{tabular}

402 